\title{
Neuroleptic-induced movement disorders in a naturalistic schizophrenia population: diagnostic value of actometric movement patterns
}

\author{
Sven Janno*1,2, Matti M Holi3 ${ }^{3}$, Katinka Tuisku ${ }^{4}$ and Kristian Wahlbeck ${ }^{2,5,6}$
}

\author{
Address: ${ }^{1}$ Department of Psychiatry, University of Tartu, Raja 31, 50417, Tartu, Estonia, ${ }^{2}$ Department of Psychiatry, University of Helsinki, \\ Tukholmankatu 8 C, 00029, Finland, ${ }^{3}$ Kellokoski Hospital, Hospital District of Helsinki and Uusimaa, FIN-04500 Kellokoski, Finland, \\ ${ }^{4}$ Mehiläinen Ltd, Siltasaarenkatu 18A, FIN-00530 Helsinki, Finland, ${ }^{5}$ STAKES National Research and Development Centre for Welfare and Health, \\ P.O.Box 220, FIN-00531 Helsinki, Finland and 'Psychiatric Unit, Vaasa Central Hospital, Hietalahdenkatu 2-4, FIN-65130 Vaasa, Finland \\ Email: Sven Janno* - sven.janno@kliinikum.ee; Matti M Holi - matti.holi@hus.fi; Katinka Tuisku - Katinka.tuisku@suomi24.fi; \\ Kristian Wahlbeck - kristian.wahlbeck@stakes.fi \\ * Corresponding author
}

Published: 18 April 2008

BMC Neurology 2008, 8:10 doi:10.1186/1471-2377-8-10
Received: 16 September 2007

Accepted: 18 April 2008

This article is available from: http://www.biomedcentral.com/I47/-2377/8/10

(C) 2008 Janno et al; licensee BioMed Central Ltd.

This is an Open Access article distributed under the terms of the Creative Commons Attribution License (http://creativecommons.org/licenses/by/2.0), which permits unrestricted use, distribution, and reproduction in any medium, provided the original work is properly cited.

\begin{abstract}
Background: Neuroleptic-induced movement disorders (NIMDs) have overlapping co-morbidity. Earlier studies have described typical clinical movement patterns for individual NIMDs. This study aimed to identify specific movement patterns for each individual NIMD using actometry.
\end{abstract}

Methods: A naturalistic population of 99 schizophrenia inpatients using conventional antipsychotics and clozapine was evaluated. Subjects with NIMDs were categorized using the criteria for NIMD found in the Diagnostic and Statistical Manual for Mental Disorders - Fourth Edition (DSM-IV).

Two blinded raters evaluated the actometric-controlled rest activity data for activity periods, rhythmical activity, frequencies, and highest acceleration peaks. A simple subjective question was formulated to test patient-based evaluation of NIMD.

Results: The patterns of neuroleptic-induced akathisia (NIA) and pseudoakathisia (PsA) were identifiable in actometry with excellent inter-rater reliability. The answers to the subjective question about troubles with movements distinguished NIA patients from other patients rather well. Also actometry had rather good screening performances in distinguishing akathisia from other NIMD. Actometry was not able to reliably detect patterns of neuroleptic-induced parkinsonism and tardive dyskinesia.

Conclusion: The present study showed that pooled NIA and PsA patients had a different pattern in lower limb descriptive actometry than other patients in a non-selected sample. Careful questioning of patients is a useful method of diagnosing NIA in a clinical setting.

\section{Background}

Globally, many schizophrenia patients still suffer from neuroleptic-induced movement disorders (NIMDs) [1-3] in spite of the increasing use of second generation antipsychotics, which in general have a lower propensity for NIMDs [4]. Although in earlier years movement adverse 
effects were even considered to be an indicator of antipsychotic action [5], today they are seen as burdening and stigmatizing phenomena that should be avoided by careful choice of treatment [6]. NIMDs, which are investigated in this study and classified in DSM-IV [7], include neuroleptic-induced akathisia (NIA), neuroleptic-induced parkinsonism (NIP) and tardive dyskinesia (TD). Pseudoakathisia (PsA) is a movement disorder with objective signs of akathisia, but without the subjective feeling of restlessness [8]. PsA is not included in the DSM-IV classification [7].

Besides motor inconvenience, NIMD can cause subjective suffering through cognitive or emotional disturbance [9]. Patients have described rigidity and dullness of thinking in association with parkinsonism [10]. Akathisia causes significant distress and is reported to be associated with suicide attempts [11] and aggression [12]. It results in reduced compliance with antipsychotic drug treatment and thus a cause of psychotic relapses [13].

The interest in the instrumental measurement of NIMDs in addition to clinical examination and observer-based rating scales has long traditions. Instrumental measurement has been reported 1) to identify more NIMDs patients than observer-based ratings [14], 2) to be more sensitive to sub-clinical motor changes [15],3) to exhibit greater linearity with regard to severity [15-17], and 4) to need less training to achieve sufficient inter-rater reliability and test-retest reliability [16].

Previous studies have mostly been conducted with selected patients and non-NIMD controls, but in chronic patients using long-term antipsychotics, different NIMD often occur together [1-3].

\section{Studies using instrumental measurement of neuroleptic- induced akathisia (NIA)}

NIA has been studied by actometry (accelerometry or actigraphy) [18-24] and by eletromyography (EMG) [25], mostly in polysomnographic studies $[26,27]$. For example, Gardos et al. [19] measured overall 24-hour motor activity in 8 NIA patients by means of an actometer strapped to the non-dominant ankle, and found that akathisia had no relationship to nocturnal activity. Diurnal motor activity analysis of wrist accelerometers worn by 16 NIA patients and by 16 non-NIA patients revealed that NIA patients had higher levels of motor activity over a two-day period [22]. Movement activity measured by accelerometers on ankles and the waist in a standardized rest activity (30 minutes) discriminated 10 pure NIA patients from themselves while in remission and also from 10 healthy controls with no overlap [21]. Actometry was able to reveal akathisia in a patient who had mostly subjective complaints and hypokinesia masked akathisia
[23]. The same method, however, did not discriminate 31 NIA patients from those without NIA in a clinical nonselected sample of 99 patients with co-morbid NIMDs [24]. The sensitivity of actometric measurement was 0.77 and specificity 0.57 at the optimal cut-off point, which was 12000 of lower limb activity count [24].

Toe tremor was more informative than finger tremor in distinguishing 6 akathisia patients from controls by actometry. Characteristic of akathisia were low frequency (less $4 \mathrm{~Hz}$ ) rhythmic foot movements [18]. No differences were found between NIA and pseudoakathisia (PsA) in accelerometric recordings [20]. PsA prevalence in chronic schizophrenia patients is $18 \%$ [28]. An EMG study using a case definition for akathisia (i.e. 10 second duration and less than $4 \mathrm{~Hz}$ in the anterior tibialis tracings) in the evaluation of 26 subjects (16 NIA patients) and yielded a sensitivity of $69 \%$ and specificity of $70 \%$ in NIA detecting [25].

\section{Studies of neuroleptic-induced parkinsonism (NIP)}

NIP has been studied by EMG $[29,30]$ and force transducers $[14,17,31]$, and NIP tremor has been studied by accelerometry [32-34]. NIP tremor occurred in the range of 5$7 \mathrm{~Hz}$ when recorded from a pair of antagonist muscles in EMG studies, and was distinguishable from the activity of TD $[29,30]$. Mean tremor frequency measured by accelerometry was over $5 \mathrm{~Hz}$ [33]. Accelerometric recordings from 14 patients in frequencies between 4 and $7 \mathrm{~Hz}$ were helpful in differentiating neuroleptic-induced tremor from other NIMD and from psychogenic tremor [32].

\section{Studies on tardive dyskinesia (TD)}

TD has been studied instrumentally by EMG $[29,30]$, force transducers $[14,16,17,31,35]$, and accelerometers [35-37]. EMG studies described the movement pattern as irregular bursts below $3 \mathrm{~Hz}$, but almost all TD patients had activity in limbs - 15 of $16[29,30]$. Instrumental measurement has been used in TD to estimate current status and treatment efficacy [35].

Qualitative actometry (analysing the frequency peak) seemed highly specific in TD patients, with a mean Abnormal Involuntary Movement Scale (AIMS) total score of 11.2 [37].

\section{Aim of the study}

Hyperkinetic movement disorders, like all neuropsychiatric disorders [19], may non-specifically increase rest-activity, and therefore a qualitative analysis of movement pattern may be the only way to use actometry for differentiating diagnostic purposes in naturalistic samples. The aim of our study was to analyze characteristic actometry patterns of NIMDs and PsA in a naturalistic schizophrenia population. 


\section{Methods}

We recruited 99 chronic schizophrenic institutionalized adult patients from a state nursing home in Estonia [3]. Inclusion criteria were a DSM-IV diagnosis of schizophrenia or schizoaffective disorder, stable antipsychotic medication (for at least one month), and an age of 18-65 years. Diagnosis was made using a semi-structured interview according to DSM-IV criteria for schizophrenia by a psychiatrist (SI) and medical records. Patients with severe somatic illness or neurological illness were excluded. Written informed consent was obtained from the subjects and the study was approved by the Ethics Review Committee on Human Research of the University of Tartu.

An experienced psychiatrist (SI) assessed all subjects to identify NIMDs (NIA, NIP, and NITD) in accordance with DSM-IV criteria [7]. PsA diagnosis was established according to Barnes and Braude [8]. NIMDs and PsA patients are in this report defined as the movement disorders group.

The temporal connection between NIMD and PsA with a neuroleptic medication was established retrospectively by interview and medical records.

Seventy nine $(79.8 \%)$ patients were receiving conventional antipsychotics (mainly haloperidol, cyclopentixol, perphenazine, levomepromazine, chlorpromazine, and also thioridazine, sulpiride, chlorprotixen, fluphenazine), while $20(20.2 \%)$ were receiving clozapine (one of whom used clozapine combined with sulpiride). No new atypical antipsychotics were used. The mean daily chlorpromazine equivalent dose [38] was $328 \mathrm{mg}$ (SD 221, range 1417).

The psychiatrist (SJ) asked one subjective question from patients concerning their problems with movements: "Do you have disturbing movement problems?" The answer was allocated to one of four categories:

a) Not to my knowledge.

b) Yes, but it doesn't disturb me

c) Yes, and it disturbs me

d) Yes, and it is very difficult to cope with

The actometric recording was performed while sitting in a standardized clinical interview for 30 minutes between 9 and $11 \mathrm{AM}$, a method described previously as measuring "controlled rest activity" [21]. Controlled rest activity is a parameter of motor activity in a situation where sitting still is adequate and expected, but not instructed or required. The actometers (PAM3, IM-systems, Baltimore, USA) were attached to the ankles of the subjects to meas- ure lower limb motor activity. Actometers are small computerized movement detectors of match-box-size which do not influence normal moving of the patient. The mode of data collection was digital integration, and the sampling rate was $40 \mathrm{~Hz}$ and the chosen epoch was $0.1 \mathrm{~s}$. PAM3 records acceleration signals exceeding 0.1G. The actometry and controlled rest activity method have been described previously by Tuisku et al. [21] and Janno et al. [24].

To test the feasibility and properties of actometric recording in a normal clinical setting we trained raters without previous experience of evaluating actometric recordings. A team of five neuropsychiatrists developed rater instructions and a data collecting form. Data evaluation training comprised two hours, followed by supervised evaluation of ten actometric recordings. Two raters (BA and AV) trained according to this procedure, and achieved an appropriate level of inter-rater reliability $(0.44$ to 1.0 , mean 0.82) during their training phase. Raters were blinded and had no access to patient data other than the actometric recording.

The two raters evaluated all study subjects' actometric activity recordings for the existence of activity periods, the duration of activity periods (activity for at least $10 \mathrm{sec}-$ onds), the existence of rhythmical activity. Raters calculated from persistent rhythmical activities three most dominant frequencies for every patient (if patients had rhythmical activity with different frequencies). Raters found the highest acceleration peaks in activity periods in the scope of 10 seconds. After calculating inter-rater reliability, a meeting between raters was held to establish consensus values for the estimated frequencies of activity periods for 27 patients. The extracted data was then assessed by KT and SJ to find any patterns for individual NIMDs and PsA. Answers to the subjective question were analyzed for a correlation with movement disorders diagnoses.

The inter-rater reliability was measured by kappa coefficients for categorical values and intra-class correlation (ICC) coefficients for continuous values. A two-way ANOVA mixed model was used to calculate ICC, so as to estimate the reliability of a single rating [39]. One-way ANOVA was performed to analyze the ability to discriminate different qualities of movement patterns. Differences between the movement disorder (NIA, NIP, TD and PsA) and the non-movement disorder groups in activity periods were analyzed by the Mann-Whitney two-tailed U-test for continuous variables (frequency, amount of periods). Chi-square analyze was used for dichotomous variables (presence of activity periods, rhythmical activity). Where necessary, Fisher's exact test was used for calculating significance. The performances of movement patterns in case 
identification were evaluated by receiver operating characteristics (ROC) analyses. The software used in analyses was SPSS 12.0 (SPSS Inc. Chicago, Illinois, USA).

\section{Results}

A total of 88 patients (89\%) showed rhythmical activity and their results were used in the analysis. Raters achieved excellent inter-rater reliability in almost all parameters of movement patterns of actometric recordings, except defining the minimal frequency of movement patterns (Table 1).

Movement disorders group patients had more activity periods in actometric recordings than other patients (Table 2). More than 95\% of NIA and PsA patients showed rhythmical activity. Patients who had movement disorder and particularly NIP, PsA and NIA patients had higher frequencies in rhythmical activity than other patients (Table 3). NIMD and PsA, except TD, patients had higher median acceleration peaks in rhythmical activity recordings than non-movement disorders group patients $(U=0.575, p=0.024)$.

The presence of rhythmical activity, amount of activity periods, maximal frequency, and highest values of acceleration peaks differentiated between the subgroups of NIMDs and PsA. The other parameters of movement patterns showed no ability to discriminate between movement disorders groups by one-way ANOVA analysis (data not shown). Presence of activity periods and rhythmical activity in actometric recordings had the best abilities to discriminate the patient group of pooled NIA and PsA (Table 2).

The PsA group differed mostly from the non-movement disorders group in regard to median number of activity periods and frequencies. The results of particular NIMD

Table I: Inter-rater reliability coefficients for actometry variables in 99 in-patients with schizophrenia: kappa for categorical and ICC coefficients for continuous measures.

\begin{tabular}{lc}
\hline & kappa \\
\hline presence of activity periods & $0.905^{*}$ \\
presence of rhythmical activity & $0.786^{*}$ \\
& ICC $(95 \% \mathrm{Cl})$ \\
amount of activity periods & $0.967(0.95 \mathrm{I}-0.978)^{*}$ \\
dominant frequency & $0.739(0.624-0.822)^{*}$ \\
second prevalent frequency & $0.787(0.672-0.864)^{*}$ \\
third prevalent frequency & $0.789(0.672-0.867)^{*}$ \\
minimal frequency & $0.35 \mathrm{I}(0.149-0.525) \#$ \\
maximal frequency & $0.83 \mathrm{I}(0.750-0.887)^{*}$ \\
highest value of acceleration peaks & $0.84 \mathrm{I}(0.768-0.893)^{*}$
\end{tabular}

$*_{\mathrm{p}}<0.001$

$\# p=0.001$ groups and non-movement disorders group are presented in Table 4.

The differences between particular movement disorder and non-movement disorder groups in the highest acceleration peak medians are presented in Table 4. Highest acceleration peak medians (i.e. greatest digital integration of acceleration) in activity periods were almost significantly $(\mathrm{p}=0.053)$ different (Mann-Whitney $\mathrm{U}=444)$ between NIP (203, interquartile range (IQ) 89, 250) and non-NIP $(116$, IQ 67,190$)$ groups. No significant differences were found between other groups.

Median values of third frequency and minimal frequency were not statistically significantly different between groups.

To evaluate screening properties of actometry against DSM-IV and PsA diagnostic criteria we used ROC analysis. The area under the ROC curve (AUC) of the lower limb activity count was 0.80 for PsA and 0.84 for pooled akathisia (NIA and PsA).

Answers to the subjective question differed between the movement disorders and the non-movement disorder group (Pearson chi-square 8.209, $\mathrm{p}=0.004$ ). The ROC curve for the screening performance of the subjective question in NIA is presented in Figure 1. ROC analysis of the subjective question for differentiating abilities showed an AUC value of 0.67 for NIMD and PsA, 0.87 for NIA, 0.52 for NIP, 0.46 for TD, and 0.25 for PsA.

Figure 1. Receiver Operating Characteristic (ROC) curves for subjective question and lower limb activity count against DSM-IV defined neuroleptic-induced akathisia (NIA).

\section{Discussion}

Our main finding was that actometry could objectively differentiate NIA and PsA patients from the non-movement disorder group and from all the other NIMD patients. Also, the subjective question on movement problems was able to detect NIA patients from all other subjects. Answers to this question were highly selective for NIA cases, but not for other NIMDs and PsA.

The strength of the study is the naturalistic non-selected patient sample. Therefore, we can generalize results to other chronic schizophrenia in-patients. It is possible that co-morbid movement disorders, existing in this real-life sample, compromise the previously reported characteristics of individual NIMDs or PsA. Therefore, a loss of differentiating ability of actometry is seen in a clinical setting like ours. 
Table 2: Presence of activity periods and rhythmical activity in differentiating neuroleptic-induced movement disorders for 99 inpatients with schizophrenia.

\begin{tabular}{lcc}
\hline & Presence of activity periods & Presence of rhythmical activity \\
\hline non-movement disorders vs. & & 2.726 \\
NIMD and PsA & 5.547 & 0.099 \\
Pearson chi-square & 0.035 & 5.574 \\
P & & 0.019 \\
NIA vs. non-NIA & 5.642 & \\
Pearson chi-square & 0.016 & \\
P & & 0.505 \\
NIP vs. non-NIP & 0.113 & 0.034 \\
Pearson chi-square & 0.714 & 1.607 \\
P & & 0.254 \\
TD vs. non-TD & 1.131 & 0.495 \\
Pearson chi-square & & 2.061 \\
P & 0.814 & 0.151 \\
PsA vs. non PsA & 0.685 & 11.027 \\
Pearson chi-square & & 0.001
\end{tabular}

A limitation of the study is that for practical reasons, the clinical diagnosis of NIMD or PsA was made and the subjective question was asked by the same clinician, which could have contaminated the investigator's judgement.

Another limitation of our study was that it could not detect the sub-clinical movement disorders, because we used the DSM-IV [7] and PsA [8,20] diagnostic criteria as the "gold standard": These criteria do not identify subclinical cases. Thus, the non-movement disorder subgroup may include sub-clinical movement disorder subjects, who were not detectable by DSM-IV criteria for NIMD. The latter is supported by the following findings: 1) even $75 \%$ of non-movement disorder subjects showed rhythmical activity which can be related to movement disorders, seldom a normal activity during rest; and 2) the non-movement disorder patients had less activity periods in recordings, but when they had, then frequencies were quite similar to NIMD or PsA (mostly TD) subjects.

\section{NIA and PsA}

In this sample, we have previously shown that quantitative actometry does not discriminate NIA patients from those without NIA [24]. Our finding contrasted with the finding of Tuisku et al. [21], who reported a good discrimination by actometry of selected NIA patients and healthy controls. It seems that the inclusion of PsA (which is a hyperactive movement disorder and similar in actometric recordings to NIA) in the non-NIA group, in accordance with DSM-IV criteria, compromised the differentiating ability of actometry in this population [24].

Table 3: Neuroleptic-induced movement disorders patterns for 99 in-patients with schizophrenia.

\begin{tabular}{|c|c|c|c|c|c|c|c|c|c|}
\hline & $\begin{array}{c}\text { Presence of } \\
\text { activity periods } \\
\mathrm{n} \%\end{array}$ & $\begin{array}{l}\text { Median amount } \\
\text { of activity } \\
\text { periods IQ* }\end{array}$ & $\begin{array}{l}\text { Presence of } \\
\text { rhythmical } \\
\text { activity n\% }\end{array}$ & $\begin{array}{c}\text { Median of } \\
\text { dominant } \\
\text { frequency } \mathrm{Hz} \\
\text { IQ* }\end{array}$ & $\begin{array}{c}\text { Median of } \\
\text { second } \\
\text { frequency } \mathrm{Hz} \\
\mathrm{IQ}^{*}\end{array}$ & $\begin{array}{c}\text { Median of third } \\
\text { frequency Hz } \\
\text { IQ* }\end{array}$ & $\begin{array}{c}\text { Median of } \\
\text { minimal } \\
\text { frequency } \mathrm{Hz} \\
\mathrm{IQ}^{*}\end{array}$ & $\begin{array}{c}\text { Median of } \\
\text { maximal } \\
\text { frequency } \mathrm{Hz} \\
\mathrm{IQ}^{*}\end{array}$ & $\begin{array}{l}\text { Median highest } \\
\text { value of } \\
\text { acceleration } \\
\text { peaks IQ* }\end{array}$ \\
\hline $\begin{array}{c}\text { non-movement } \\
\text { disorders } \mathrm{n}=32\end{array}$ & $\begin{array}{c}25 \\
78 \%\end{array}$ & $\frac{2}{1.00-7.63}$ & $\begin{array}{c}24 \\
75 \%\end{array}$ & $\begin{array}{c}0.50 \\
0.40-0.59\end{array}$ & $\begin{array}{c}0.43 \\
0.40-0.61\end{array}$ & $\begin{array}{c}0.55 \\
0.48-0.78\end{array}$ & $\begin{array}{c}0.33 \\
0.30-0.45\end{array}$ & $\begin{array}{c}0.65 \\
0.50-0.98\end{array}$ & $\begin{array}{c}106 \\
57-193\end{array}$ \\
\hline $\begin{array}{c}N I A \\
n=31\end{array}$ & $\begin{array}{c}31 \\
100 \%\end{array}$ & $\begin{array}{c}13 \\
5.00-22.00\end{array}$ & $\begin{array}{l}30 \\
97 \%\end{array}$ & $\begin{array}{c}0.58 \\
0.40-1.01\end{array}$ & $\begin{array}{c}0.60 \\
0.45-0.80\end{array}$ & $\begin{array}{c}0.70 \\
0.49-1.01\end{array}$ & $\begin{array}{c}0.38 \\
0.30-0.45\end{array}$ & $\begin{array}{c}1.15 \\
0.74-2.18\end{array}$ & $\begin{array}{c}177 \\
81-226\end{array}$ \\
\hline $\begin{array}{c}\text { NIP } \\
n=23\end{array}$ & $\begin{array}{l}20 \\
87 \%\end{array}$ & $\stackrel{8}{1.00-14.50}$ & $\begin{array}{c}16 \\
70 \%\end{array}$ & $\begin{array}{c}0.75 \\
0.50-0.95\end{array}$ & $\begin{array}{c}0.73 \\
0.51-4.11\end{array}$ & $\begin{array}{c}0.93 \\
0.60-1.09\end{array}$ & $\begin{array}{c}0.40 \\
0.35-0.49\end{array}$ & $\begin{array}{c}1.05 \\
0.65-2.26\end{array}$ & $\begin{array}{c}216 \\
140-250\end{array}$ \\
\hline $\begin{array}{c}\text { TD } \\
\mathrm{n}=32\end{array}$ & $\begin{array}{c}30 \\
94 \%\end{array}$ & $\begin{array}{c}9.75 \\
3.00-16.75\end{array}$ & $\begin{array}{l}29 \\
91 \%\end{array}$ & $\begin{array}{c}0.55 \\
0.40-0.80\end{array}$ & $\begin{array}{c}0.55 \\
0.45-0.93\end{array}$ & $\begin{array}{c}0.65 \\
0.46-0.95\end{array}$ & $\begin{array}{c}0.40 \\
0.30-0.45\end{array}$ & $\begin{array}{c}0.95 \\
0.63-2.03\end{array}$ & $\begin{array}{c}125 \\
75-206\end{array}$ \\
\hline $\begin{array}{c}\text { PsA } \\
\mathrm{n}=19\end{array}$ & $\begin{array}{c}18 \\
95 \%\end{array}$ & $\begin{array}{c}16 \\
10.50-25.50\end{array}$ & $\begin{array}{c}18 \\
95 \%\end{array}$ & $\begin{array}{c}0.80 \\
0.50-1.53\end{array}$ & $\begin{array}{c}0.80 \\
0.49-1.00\end{array}$ & $\begin{array}{c}0.60 \\
0.49-1.04\end{array}$ & $\begin{array}{c}0.40 \\
0.30-0.43\end{array}$ & $\begin{array}{c}1.15 \\
0.75-2.58\end{array}$ & $\begin{array}{c}127 \\
79-208\end{array}$ \\
\hline $\begin{array}{c}\text { All patients } \\
\mathrm{n}=99\end{array}$ & $\begin{array}{c}88 \\
89 \%\end{array}$ & $\frac{8}{2.00-17.50}$ & $\begin{array}{c}83 \\
84 \%\end{array}$ & $\begin{array}{c}0.55 \\
0.40-0.80\end{array}$ & $\begin{array}{c}0.55 \\
0.40-0.80\end{array}$ & $\begin{array}{c}0.65 \\
0.50-0.98\end{array}$ & $\begin{array}{c}0.35 \\
0.30-0.45\end{array}$ & $\begin{array}{c}0.90 \\
0.60-1.45\end{array}$ & $\begin{array}{c}129 \\
80-213\end{array}$ \\
\hline
\end{tabular}

* Interquartile range 
Table 4: The differences in median values of actometric pattern qualities of particular neuroleptic induced movement disorders from non-movement disorder group for 99 in-patients with schizophrenia

\begin{tabular}{|c|c|c|c|c|c|}
\hline & amount of activity periods & dominant frequency & second frequency & maximal frequency & median maximum amplitude \\
\hline NIA median & 13 & 0.58 & 0.60 & 1.15 & 177 \\
\hline non-NIMD median & 2 & 0.50 & 0.43 & 0.65 & 106 \\
\hline Mann-Whitney U & 207 & 262 & 153 & 177 & 277 \\
\hline $\mathrm{P}$ & $<0.001$ & 0.084 & 0.017 & 0.001 & 0.040 \\
\hline NIP median & 8 & 0.75 & 0.73 & 1.05 & 216 \\
\hline non-NIMD median & 2 & 0.50 & 0.43 & 0.65 & 106 \\
\hline Mann-Whitney U & 282 & 127 & 58 & 143 & 145 \\
\hline$P$ & 0.140 & 0.040 & 0.009 & 0.106 & 0.023 \\
\hline TD median & 9.75 & 0.55 & 0.55 & 0.95 & 127 \\
\hline non-NIMD median & 2 & 0.50 & 0.43 & 0.65 & 106 \\
\hline Mann-Whitney U & 294 & 267 & 163 & 209 & 305 \\
\hline$p$ & 0.003 & 0.145 & 0.030 & 0.013 & 0.110 \\
\hline PsA median & 16 & 0.8 & 0.8 & 1.15 & 144 \\
\hline non-NIMD median & 2 & 0.50 & 0.43 & 0.65 & 106 \\
\hline Mann-Whitney U & 87 & 103 & 82 & 92 & 156 \\
\hline$P$ & $<0.001$ & 0.004 & 0.011 & 0.002 & 0.042 \\
\hline NIA and PsA median & 15.75 & 0.68 & 0.60 & 1.15 & 155 \\
\hline non-NIMD median & 2 & 0.50 & 0.43 & 0.65 & 106 \\
\hline Mann-Whitney U & 641 & 364 & 235 & 269 & 433 \\
\hline P & 0.003 & 0.011 & 0.006 & $<0.001$ & 0.017 \\
\hline
\end{tabular}

Our findings are consistent with a previous accelerometric study [20], which found no differences between clinical observations and accelerometric recordings of NIA and PsA. We have previously reported that in NIA the area under the ROC curve was 0.68 [24] for the actometric activity count, and we now report that in PsA the discriminatory power of actometry is better (ROC 0.80 ). The

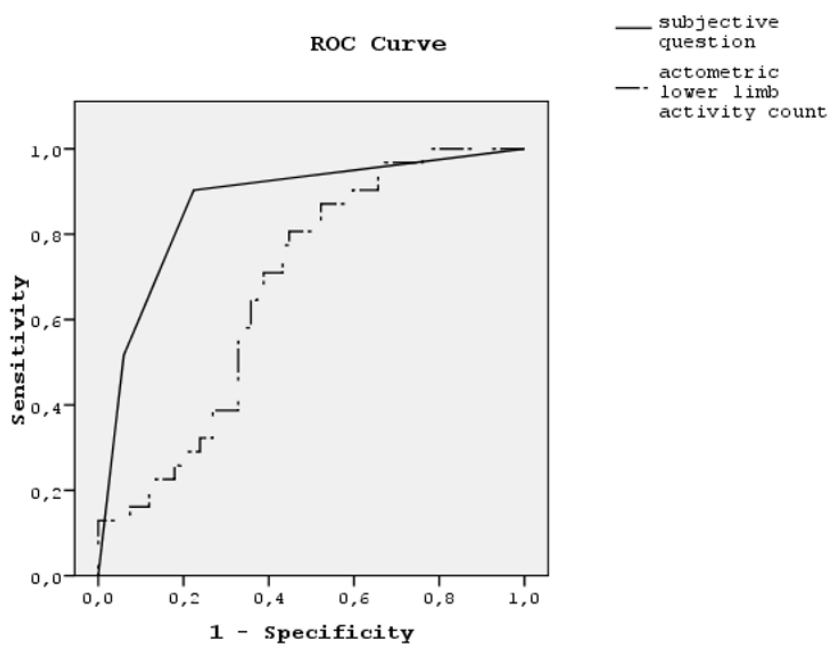

Figure I

Receiver Operating Characteristic (ROC) curves for subjective question and lower limb activity count against DSM-IV defined neuroleptic-induced akathisia (NIA). overall activity count differentiated the pooled NIA and PsA from other NIMD and non-movement disorder patients.

Differences in median values of the actometric count for the PsA group and non-movement disorder group validates the diagnosis of PsA. These patients have higher frequency movements than other patients, but are not aware of them (according to answers to our subjective question). They have difficulties in noticing their disturbance, which clearly distinguishes this disorder from NIA.

The subjective question was selective for NIA cases, but not for other NIMDs or PsA. This is explained by the subjective component of NIA. Asking such a subjective question offers a cost-effective way of screening NIA with good screening ability. Although the single question has its limitations and is not enough to evaluate the various subjective discomforts associated with NIMD. Our results show that even single question can be a useful method of diagnosing NIA in a clinical setting.

\section{NIP}

The parkinsonian tremor shows rhythmical activity in accelerometric recordings, which discriminates NIP patients from non-movement disorder patients. NIP patients had higher peaks of accelerations in activity periods than other patients. Comparing the NIP group with the non-movement disorder group made this finding more significant. Parkinsonian hypokinesia, unlike other NIMD or PsA, shows less movements (overall activity 
count) in actometric recordings, which we have presented previously [34]. In our study, the frequencies of rhythmic activity in NIP were much lower (median below $1 \mathrm{~Hz}$ ), than reported by previous studies (above $4 \mathrm{~Hz}$ ) [29,33]. One possible explanation is that by measuring lower limb activity in a sitting position we could not detect the high frequency NIP tremor, which in previous studies was measured from upper limbs by actometry [33]. There may have been a high frequency tremor (close to $10 \mathrm{~Hz}$ ) in our sample that we were not able to detect with our method due to the limitation of the time window of our actometers.

\section{TD}

TD usually affects only some body segments, mostly the orofacial region and sometimes the legs. Recording of ankle movements gave little information for detecting TD, despite the fact that the movement pattern of TD has more activity periods, rhythmical activity, and somewhat higher frequencies than non-movement disorder patterns.

\section{Conclusion}

The actometric recording and analysing of the standardized left-leg motor activity is moderately time-consuming, but it may have limited use. The method can be used in NIMD and PsA patients for differentiating akathisia (pooled NIA and PsA) from other patients, but not for discriminating between NIA and PsA. Our study employed ankle recording only, and actometric recording from the ankle and wrist simultaneously may give more information for detecting NIMD in the schizophrenia patient population. Actometry allows a quantifiable recording of current state of movement disorders and is thus useful in research settings. Further research should focus on the ability of actometry to show change in the patient condition. Initial studies in this direction have already been done $[21,35]$.

Actometry is useful for measuring change in the overall movement count or patterns after a change of risk factors (dosage, antipsychotic type, time course etc) in experimental conditions, and further research can show the ability of actometric data to drive treatment decisions in a clinical setting.

The present study showed that pooled NIA and PsA patients had different patterns in lower limb descriptive actometry than other patients in a non-selected sample. Careful questioning of patients is a useful and clinically significant method of diagnosing NIA in a clinical setting.

\section{Competing interests}

The author(s) declare that they have no competing interests.

\section{Authors' contributions}

SJ contributed to the study design, collected the data, contributed to the analyses and data interpretation, made the literature search and was responsible for manuscript preparation. $\mathrm{MMH}$ contributed to study design, analyses, data interpretation, and manuscript preparation. KT contributed to study design, statistical analysis, data interpretation and manuscript preparation. KW supervised the study design and contributed to statistical analysis, data interpretation and preparation of the manuscript.

\section{Acknowledgements}

We thank Birgit Aumeste and Andres Valk for rating the raw actometric data.

The study was supported by a grant from Finska Läkaresällskapet (Finnish Medical Society).

\section{References}

I. McCreadie RG, Robertson LJ, Wiles DH: The Nithsdale schizophrenia surveys. IX: Akathisia, parkinsonism, tardive dyskinesia and plasma neuroleptic levels. Br J Psychiatry 1992, 160:793-799.

2. Van Harten PN, Matroos GE, Hoek HW, Kahn RS: The prevalence of tardive dystonia, tardive dyskinesia, parkinsonism and akathisia. The Curacao Extrapyramidal Syndromes Study: I. Schizophr Res 1996, 19:195-203.

3. Janno S, Holi MM, Tuisku K, Wahlbeck K: Prevalence of neuroleptic-induced movement disorders in chronic schizophrenia patients. Am J Psychiatry 2004, 161:160-163.

4. Barnes TR, McPhillips MA: Critical analysis and comparison of the side-effect and safety profiles of the new antipsychotics. British Journal of Psychiatry 1999, I74(38S):34-43.

5. Haase $H J$ : The purely neuroleptic effects and its relation to the "neuroleptic threshold". Acta Psychiatr Belg 1978, 78:19-36.

6. Whitehorn D, Kopala LC: Neuromotor dysfunction in early psychosis. Annals of Clinical Psychiatry 2002, I 4:1 13-121.

7. American Psychiatric Association: Diagnostic and Statistical Manual of Mental Disorders fourth edition. Washington DC: American Psychiatric Press; 2000.

8. Barnes TRE, Braude WM: Akathisia variants and tardive dyskinesia. Arch Gen Psychiatry 1985, 42:874-878.

9. Dollfus $S$, Ribeyre JM: Objective and subjective extrapyramidal side effects in schizophrenia: their relationships with negative and depressive symptoms. Psychopathology 2000, 33:125-130.

10. Krausz M, Moritz SH, Naber D, Lambert M, Andresen B: Neuroleptic-induced extrapyramidal symptoms are accompanied by cognitive dysfunction in schizophrenia. Eur Psychiatry 1999, 14:84-88.

II. Drake RE, Ehrlich J: Suicide attempts associated with akathisia. Am J Psychiatry 1985, I42:499-50I.

12. Ratey J, Gordon A: The psychopharmacology of aggression: toward a new day. Psychopharmacol Bull 1993, 29:65-73.

13. Van Putten T: Why do schizophrenic patients refuse to take their drugs? Arch Gen Psychiatry 1974, 3 I:67-72.

14. Cortese L, Caligiuri MP, Malla AK, Manchanda R, Takhar J, Haricharan $\mathrm{R}$ : Relationship of neuromotor disturbances to psychosis symptoms in first episode neuroleptic-naïve schizophrenia patients. Schizophr Res 2005, 75:65-75.

15. Lohr JB, Caligiuri MP: Quantitative instrumental measurement of tardive dyskinesia: a review. Neuropsychopharmacology 1992, 6:23I-239.

16. Caligiuri MP, Lohr JB, Rotrosen J, Adler L, Lavori P, Edson R, Tracy K: Reliability of an instrumental assessment of tardive dyskinesia: results from VA Cooperative study \#394. Psychopharmacology 1997, I32:61-66.

17. Dean CE, Russell J, Kuskowski MA, Caligiuri MP, Nugent S: Clinical rating scales and instruments: How do they compare in 
assessing abnormal, involuntary movements? Journal of Clinical Psychopharmacology 2004, 24:298-304.

18. Braude WM, Charles IP, Barnes TRE, Coarse, jerky foot tremor: Tremographic investigation of an objective sign of acute akathisia. Psychopharmacology 1984, 82:95-10I.

19. Gardos G, Teicher MH, Lipinski JF, Matthews J, Morrison L, Conley C, Cole JO: Quantitative assessment of psychomotor activity in patients with neuroleptic-induced akathisia. Progress in Neuro-Psychopharmacology \& Biological Psychiatry 1992, 16:27-37.

20. Rapoport A, Stein D, Grinshpoon A, Elizur A: Akathisia and pseudoakathisia: Clinical observations and accelerometric recordings. J Clin Psychiatry 1994, 55:473-477.

21. Tuisku K, Lauerma H, Holi MM, Markkula J, Rimon R: Measuring neuroleptic-induced akathisia by three-channel actometry. Schizophr Res 1999, 40: 105-110.

22. Poyurovsky M, Nave R, Epstein R, Tzischinsky O, Schneidman M, Barnes TR, Weizman A, Lavie P: Actigraphic monitoring (actigraphy) of circadian locomotor activity in schizophrenic patients with acute neuroleptic-induced akathisia. Eur Neuropsychopharmacol 2000, 10:17I-176.

23. Tuisku K, Lauerma H, Holi MM, Honkonen T, Rimon R: Akathisia masked by hypokinesia. Pharmacopsychiatry 2000, 33:147- I49.

24. Janno S, Holi MM, Tuisku K, Wahlbeck K: Comparison of actometry and Barnes Akathisia Rating Scale (BARS) in neuroleptic-induced akathisia. Eur Neuropsychopharmacol 2005, I 5:39-4I.

25. Cunningham SL, Winkelman JW, Dorsey CM, Lukas SE, Richardson GS, Sholar MB, Hunt A: An electromyographic marker for neuroleptic-induced akathisia: preliminary measures of sensitivity and specificity. Clinical Neuropharmacology 1996, 19:32I-332.

26. Lipinski JF, Hudson Jl, Cunningham SL, Aizley HG, Keck PE, Mallya G, Aranow R, Lukas SE: Polysomnographic characteristics of neuroleptic-induced akathisia. Clin Neuropharmacol |99|, |4:4|3-4|9.

27. Walters AS, Hening W, Rubinstein M, Chokroverty S: A clinical and polysomnographic comparison of neuroleptic-induced akathisia and the idiopathic restless legs syndrome. Sleep 1991, 14:339-345.

28. Halstead S, Barnes T, Speller J: Akathisia: Prevalence and associated dysphoria in an in-patient population with chronic schizophrenia. Br J Psychiatry 1994, I64:177-183.

29. Bathien N, Koutlidis RM, Rondot P: EMG patterns in abnormal involuntary movements induced by neuroleptics. I Neurol Neurosurgery Psychiatry 1984, 47:1002-1008.

30. Rondot P, Bathien N: Movement disorders in patients with coexistent neuroleptic-induced tremor and tardive dyskinesia: EMG and pharmacological study. Adv Neurol 1986, 45:361-366.

31. Caligiuri MP, Lohr JB, Bracha S, Jeste D: Clinical and instrumental assessment of neuroleptic-induced parkinsonism in patients with tardive dyskinesia. Biol Psychiatry I99|, 29:।39-148.

32. Rapoport A, Stein D, Shamir E, Schwartz M, Levine J, Elizur A, Weizman A: Clinico-tremorgraphic features of neurolepticinduced tremor. Int Clin Psychopharmacol 1998, 13:1 I5-120.

33. Caligiuri MP, Tripp RM: A portable hand-held device for quantifying and standardizing tremor assessment. J Med Eng Techn 2004, 28:254-262

34. Janno S, Holi MM, Tuisku K, Wahlbeck K: Validity of SimpsonAngus Scale (SAS) in a naturalistic schizophrenia population. BMC Neurol 2005, 5(I):5.

35. Adler LA, Rotrosen J, Edson R, Lavori P, Lohr J, Hitzemann R, Raisch D, Caligiuri MP, Tracy K, the Veterans Affairs Cooperative Study \#394 Study Group: Vitamin E treatment for tardive dyskinesia. Arch Gen Psychiatry 1999, 56:836-84I.

36. Denney D, Casey D: An objective method for measuring dyskinetic movements in tardive dyskinesia. Electroencephalogr Clin Neurophysiol 1975, 38:645-646.

37. Tryon WW, Pologe B: Accelerometric assessment of tardive dyskinesia. Am J Psychiatry 1987, I 44:I584-I 587.

38. Bazire S: Psychotropic Drug Directory Dinton, UK: Quay Books; 2000.

39. Fleiss JL: Statistical Methods for Rates and Proportions Second edition. New York: John Wiley \& Sons;; 1981.

\section{Pre-publication history}

The pre-publication history for this paper can be accessed here: http://www.biomedcentral.com/1471-2377/8/10/prepub

Publish with Biomed Central and every scientist can read your work free of charge

"BioMed Central will be the most significant development for disseminating the results of biomedical research in our lifetime. "

Sir Paul Nurse, Cancer Research UK

Your research papers will be:

- available free of charge to the entire biomedical community

- peer reviewed and published immediately upon acceptance

- cited in PubMed and archived on PubMed Central

- yours - you keep the copyright
BioMedcentral 